\title{
Project Morpheus: Lessons Learned in Lander Technology Development
}

\author{
Jon B. Olansen, $\mathrm{PhD}^{1}$, Stephen R. Munday ${ }^{2}$ and Jennifer D. Mitchell ${ }^{3}$ \\ NASA Johnson Space Center, Houston, TX 77546
}

\begin{abstract}
NASA's Morpheus Project has developed and tested a prototype planetary lander capable of vertical takeoff and landing, that is designed to serve as a testbed for advanced spacecraft technologies. The lander vehicle, propelled by a LOX/Methane engine and sized to carry a $500 \mathrm{~kg}$ payload to the lunar surface, provides a platform for bringing technologies from the laboratory into an integrated flight system at relatively low cost. Designed, developed, manufactured and operated in-house by engineers at Johnson Space Center, the initial flight test campaign began on-site at JSC less than one year after project start. After two years of testing, including two major upgrade periods, and recovery from a test crash that caused the loss of a vehicle, flight testing will evolve to executing autonomous flights simulating a $500 \mathrm{~m}$ lunar approach trajectory, hazard avoidance maneuvers, and precision landing, incorporating the Autonomous Landing and Hazard Avoidance (ALHAT) sensor suite. These free-flights are conducted at a simulated planetary landscape built at Kennedy Space Center's Shuttle Landing Facility. The Morpheus Project represents a departure from recent NASA programs and projects that traditionally require longer development lifecycles and testing at remote, dedicated testing facilities. This paper expands on the project perspective that technologies offer promise, but capabilities offer solutions. It documents the integrated testing campaign, the infrastructure and testing facilities, and the technologies being evaluated in this testbed. The paper also describes the fast pace of the project, rapid prototyping, frequent testing, and lessons learned during this departure from the traditional engineering development process at NASA's Johnson Space Center.
\end{abstract}

\section{INTRODUCTION}

NASA's strategic goal of extending human activities across the solar system requires an integrated architecture to conduct human space exploration missions beyond low earth orbit (LEO). This architecture must include advanced, robust in-space transit and landing vehicles capable of supporting a variety of lunar, asteroid and planetary missions; automated hazard detection and avoidance technologies that reduce risk to crews, landers and precursor robotic payloads; and in-situ resource utilization (ISRU) to support crews during extended stays on extraterrestrial surfaces and provide for their safe return to earth. The Advanced Exploration Systems (AES) Program portfolio within NASA includes several fast-paced, milestone-driven projects that are developing these necessary capabilities and, when integrated with subsystem technologies developed by Science Mission Directorate (SMD) investments, can form the basis for a lander development project. Specifically, the Morpheus, Autonomous Landing \& Hazard Avoidance Technology (ALHAT), and Regolith \& Environment Science \& Oxygen \& Lunar Volatiles Extraction (RESOLVE) projects provide the technological foundation for lunar surface demonstration missions later in this decade, and for key components of the greater exploration architecture required to move humans beyond LEO.

\footnotetext{
${ }^{1}$ Morpheus Project Manager, Mail Stop EA32, AIAA Senior Member

${ }^{2}$ Morpheus Deputy Project Manager, Mail Stop EA32

${ }^{3}$ Morpheus Systems Engineering \& Integration Manager, Mail Stop EA34
} 
The Morpheus Project provides an integrated vertical test bed (VTB) platform for advancing multiple subsystem technologies. While technologies offer promise, capabilities offer potential solutions for future human exploration beyond LEO. Morpheus provides a bridge for evolving these technologies into capable systems that can be demonstrated and tested. This paper describes the activities of the Morpheus Project, ongoing integration with ALHAT through FY12-13, and expectations for the future, with the goal of developing and demonstrating these human spaceflight capabilities with robotic missions to the lunar surface.

The Morpheus Project provides a liquid oxygen (LOX) / liquid methane (LCH4) propelled vehicle that, when leveraging subsystem designs developed by other VTBs such as the Marshall Space Flight Center's (MSFC) Mighty Eagle Lander, may be developed into reusable platforms for in-space transit and/or planetary landing for multiple missions and payload capacities. Such platforms could directly support robotic missions and would eventually mature into capabilities advantageous for manned missions.

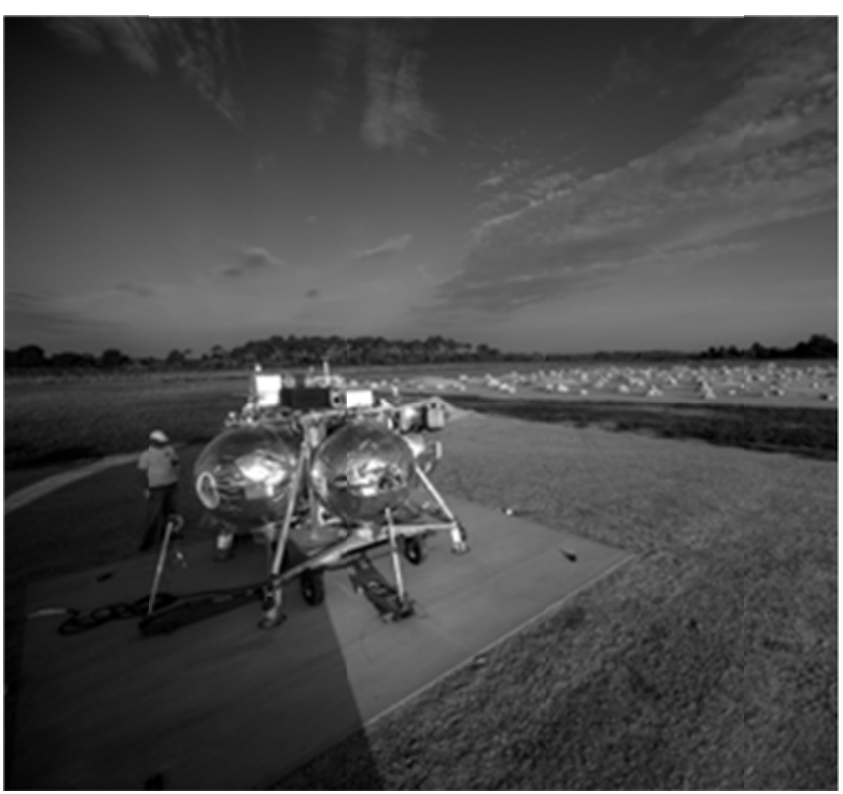

Figure 1 - Morpheus 'Alpha' Vehicle is prepared for testing at Kennedy Space Center in August 2012.

The LOX/methane propulsion system is one of two key technologies that Morpheus is designed to integrate and demonstrate. The Morpheus LOX/methane propulsion system can provide a specific impulse during space flight of up to 321 seconds; it is clean-burning, non-toxic, and cryogenic, but space-storable. Additionally, for future space missions the lox and/or methane could be produced in situ on planetary surfaces, and the oxygen is compatible onboard with life support systems and power generation. These attributes make LOX/methane an attractive propulsion technology for a lander of this scale.

ALHAT, the primary Morpheus payload, provides the second key technology: autonomous landing and hazard avoidance. When landing autonomously on any planetary or other surface, the vehicle must be able to identify a safe landing site that is free of large boulders, rocks, craters, or highly sloping surfaces. Morpheus is designed to carry ALHAT sensors and software supporting tests that will demonstrate an integrated vehicle capability to perform these tasks.

\section{SYSTEM DESCRIPTION}

The VTB system elements include the flight test vehicle, ground systems, and operations.

\section{A. Vehicle}

Morpheus design and development began in June 2010, primarily by an in-house team at NASA's Johnson Space Center. The current iteration is the Morpheus '1.5 Bravo' vehicle, and system description references the current vehicle build.

Morpheus is a "quad" lander design with four tanks and a single engine. The primary structure consists of welded aluminum box beams, machined parts, and aluminum plate. The landing struts have honeycomb crush pads in the feet to attenuate landing loads. The propellant tanks are made of welded aluminum hemispheres. The avionics and GN\&C components are located on a plate that spans the top deck of the primary structure.

The propulsion system uses an impinging element-type engine design, with liquid oxygen and methane as the propellants. The engine is film-cooled and operates as a blow-down system producing up to $5000 \mathrm{lbf}$ of thrust. Two orthogonal electromechanical actuators (EMAs) gimbal the engine to provide thrust vector control of lateral translation and pitch and yaw attitudes. LOX/LCH4 pencil thrusters fed from the same propellant tanks provide roll control with a redundant set of helium jets that use the pressurized helium in the propellant tanks onboard as a backup system. Varying the engine throttle setting provides vertical control of ascent and descent rates.

The avionics and power subsystems include the flight computer, data recording, instrumentation, communications, cameras, and batteries. The flight computer is an AITech S900 CompactPCI board with a PowerPC 750 processor. Up to 16 GB of data can be stored on board. Data buses include RS-232, RS-422, Ethernet, 
and MIL-STD-1553. Multiple channels of analog and digital inputs are used for both operational and developmental flight instrumentation, including temperature sensors, pressure transducers, tri-axial accelerometers, and strain gauges. Wireless communications between ground operators and the vehicle use a spread spectrum frequency band. Two on-board cameras provide views of the engine firing during testing. Eight lithium polymer batteries provide vehicle power.

The GN\&C sensor suite includes a Javad Global Positioning System (GPS) receiver, an International Space Station (ISS) version of Honeywell's Space Integrated GPS/INS (SIGI), a Systron Donner SDI500 Inertial Measurement Unit (IMU), and an Acuity laser altimeter. The vehicle is able to determine position to less than one meter, velocity to less than three $\mathrm{cm} / \mathrm{second}$, and attitude knowledge within 0.05 degrees.

The vehicle software is architected around Goddard Space Flight Center's (GSFC) Core Flight Software (CFS). GSFC designed CFS as a set of reusable software modules in a flexible framework that can be adapted to various space applications. Morpheus software developers built upon CFS by adding custom application code unique to the Morpheus vehicle and mission design.

The initial Morpheus VTB 1.0 configuration was tested from April 2011 through August 2011. In late 2011 and early 2012, the team began upgrading the VTB to the Morpheus 1.5 configuration, including sequentially higher performance HD4 and HD5 engines, an improved avionics and power distribution design, the addition of LOX/methane thrusters for roll control, and the incorporation of the ALHAT sensors and software. In August 2012, the original vehicle was lost in a test crash. The vehicle was rebuilt with over 70 upgrades and is designated as the Morpheus 1.5 'Bravo' vehicle. This vehicle configuration is currently in testing as described in later sections. A 'Charlie' vehicle is also under construction.

\section{B. ALHAT Payload}

One of the primary objectives of the Morpheus project is to demonstrate and advance the Technology Readiness Level (TRL) of precision landing and hazard avoidance capabilities developed by the ALHAT system. The ALHAT project has been developing an integrated Autonomous Guidance, Navigation, and Control (AGNC) hardware and software system capable of detecting and avoiding surface hazards and autonomously guiding a manned or unmanned space vehicle to a safe touchdown within 90 meters of a pre-designated planetary or asteroid site. This payload project has been conducted with a team of technical experts from JSC, Draper Laboratory, Jet Propulsion Laboratory (JPL), Langley Research Center (LaRC), and the Applied Physics Laboratory at Johns Hopkins University.

ALHAT is using an onboard laser altimeter and flash Light Detection and Ranging (LIDAR) for the onboard sensors to perform Terrain Relative Navigation (TRN) and Hazard Relative Navigation (HRN). A flash LIDAR flashes a very quick laser beam over a planetary surface area of approximately $100 \times 100$ meters. This cross-cutting technology is also being employed by commercial ISS supply companies and NASA's Orion project for automated rendezvous and docking (AR\&D). The photons emitted from the LIDAR strike the surface of the target object or surface and return to a timing detector grid, giving very precise range and bearing measurements for each photon 30 times a second. These three dimensional measurements provide elevation information for each small segment of the surface, thus producing a digital elevation map that can be used to determine hazards to the landing vehicle. Software algorithms interpret this information and

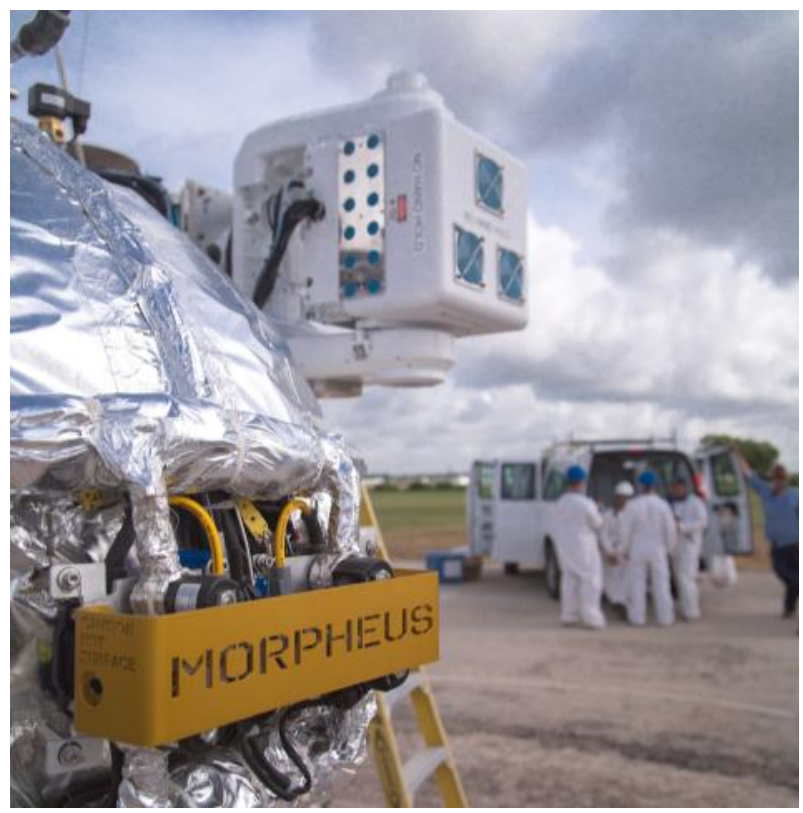

Figure 2 - ALHAT Hazard Detection System mounted on the Morpheus ‘Bravo’ vehicle determine the safest regions to land without hazards. To avoid interference from surface dust while descending to a safe region, the ALHAT design supplements the flash LIDAR with a Doppler LIDAR velocimeter, an IMU, and software to ensure precise measurements of lander attitude, altitude, and velocity are available at all times during the final phases of landing. These surface relative measurements provide the onboard navigation system with sufficient accuracy during last 30 seconds of the descent phase to navigate to the chosen safe region regardless of any dust disturbed by the descent engine. 


\section{Ground Systems}

The VTB flight complex (VFC) includes 20' x 20' concrete pads located on a section of the JSC antenna range near an old Apollo-era antenna tower. About 2000 feet away is the Morpheus control center for on-site field testing at JSC, the small 2-story building 18 that was formerly used for rooftop GPS testing and storage. The main upstairs room has a window that looks directly out onto the test area, making it highly suitable as the operations "front room," configured with three rows of computer tables for operator workstations. An adjacent room serves as the "back room" for support personnel.

The operator workstations use GSFC's Integrated Test and Operations System (ITOS) ground software. Like CFS, ITOS was developed as ground control and display software for GSFC space vehicles and has been made available to other projects at NASA. ITOS is individually configured on each workstation to display vehicle telemetry and information unique to each operator position.

During each test, the Morpheus Project streams mission telemetry, voice loops, and video from the testing control center to JSC's Mission Control Center (MCC) over dedicated wireless and wired networks. From there, data and video can be made available to internal and external networks for NASA personnel and the general public.

A thrust termination system (TTS) is employed both for range safety and independent test termination purposes. Closing either of two motorized valves in the TTS will shut off the flow of liquid oxygen and methane to the engine and terminate engine thrust. These TTS valves are completely independent from the rest of the vehicle systems and commanded using separate Ultra High Frequency (UHF) radios. The commands to initiate thrust termination are sent from a control unit located in the operations center during any live engine testing.

Ground systems also include propulsion ground support equipment (GSE). The consumables required for an engine test include liquid oxygen, liquefied natural gas, helium, liquid nitrogen, and gaseous nitrogen. The power GSE is a portable ground power cart that is used to supply power to the vehicle until the test procedures call for a switch to internal vehicle power. The ground power cart uses heavy duty batteries and can provide up to 72 amphours of power for pre- and post-test

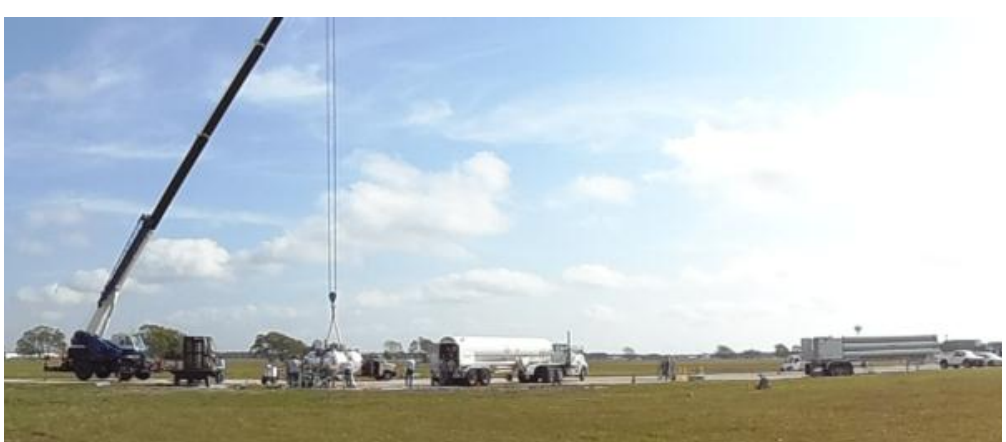

Figure 3 - Typical Morpheus ground support equipment activities. The mechanical GSE includes a rented crane for tethered or hot fire / hold-down testing. For tethered tests, an energy absorber is placed between the vehicle and the crane boom arm. The energy absorber is an aluminum piston and cylinder with cardboard honeycomb material that can attenuate up to 10,000 lb. This load attenuation protects the vehicle and crane structures in the event engine thrust needs to be terminated prematurely, causing the vehicle to drop to the end of the tether.

Ground systems also include a variety of transportation assets, provided primarily by JSC Center Operations.

\section{Operations}

The final element of the Morpheus system is Operations. Nine primary operator positions are staffed by team members: test conductor (TC), operator (OPS), propulsion (PROP), avionics, power and software (APS), guidance, navigation and control (GNC), ground control (GC), two range safety officers (RSO-1 and RSO-2), and the flight manager (FM). During tests with payloads aboard, another position may be included, such as one for ALHAT. Each position is certified through specific training.

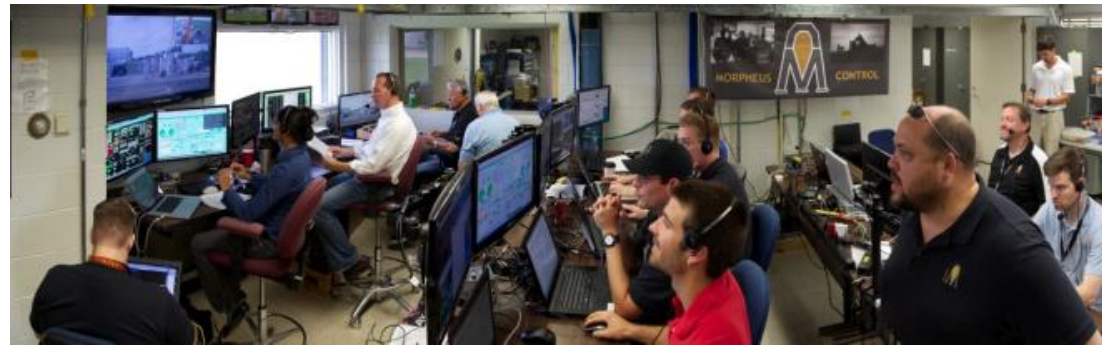

Figure 4 - Morpheus Control Center
Certification is also required for three pad crew (PAD) positions. PAD- 1 is the pad crew leader, responsible for communicating directly with the test conductor during operations and ensuring each procedural step is executed at the pad. PAD-2 and PAD-3 provide support to PAD1 , and conduct all handling of

4

American Institute of Aeronautics and Astronautics: SPACE 2013 
cryogenic fluids and most other consumables.

On test days, many other JSC and Morpheus team personnel serve in various functions. JSC riggers support vehicle transportation and crane operations. Support personnel for each subsystem monitor data or help out during testing in the "back room" of the control center. Other team members stand by for potential troubleshooting if problems arise.

\section{MORPHEUS TEST CAMPAIgN}

Morpheus testing includes three major types of integrated tests: hot-fire, tether, and free-flight.

\section{A. Hot-fire Testing}

During hot-fire testing the vehicle is completely restrained from movement and the primary focus is to test the LOX/methane propulsion system. In this configuration a crane is used to suspend the vehicle above the ground to provide clearance for the vehicle exhaust plume. The vehicle is also constrained from below using straps anchored to the ground that prevent vertical and lateral vehicle motion.

Figure 5 shows the vehicle during test in the hot-fire configuration. The vehicle is suspended approximately 20' above a concrete pad by a crane outfitted with

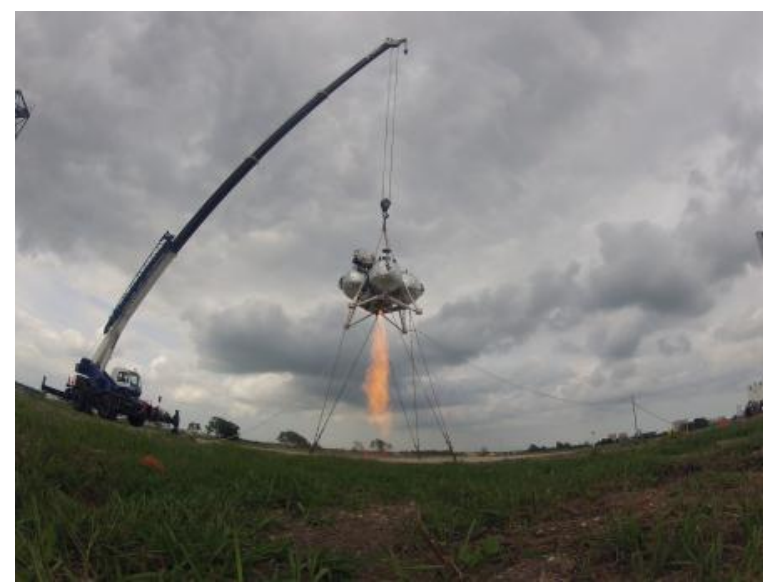

Figure 5 - Morpheus in standard Hot-fire Test Configuration

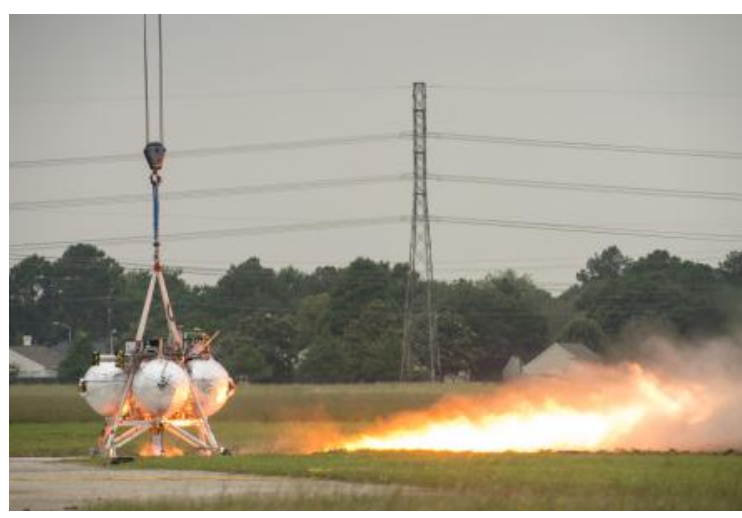

Figure 6 - Morpheus in Ground Hot-fire Test Configuration

shielding to prevent damage from flames or debris during the test firing. Additional restraints are attached below the vehicle made of nylon overwrapped with fireproof insulation or chains.

The objectives for hot-fire tests include demonstration of the igniter, engine ignition, performance at varied throttle settings and burn duration tests. The Morpheus project test approach limits testing on a dedicated engine test stand and emphasizes a quick transition to integrated vehicle tests. Testing on the vehicle promotes optimization of engine performance for the actual vehicle propulsion feed system instead of the test stand system. It also allows gimbal sweeps to evaluate the integrated performance of the actuators under load. The majority of engine characterization is conducted on the vehicle, essentially making the hot-fire configuration the primary engine test stand for the Morpheus Project.

A second hot-fire configuration was also developed to test the thermal and vibroacoustic environments at liftoff. In this case, the vehicle remains static on the ground, chained to the launch pad. The engine is run for only a few seconds at maximum thrust to envelope any environments expected on an actual launch attempt. One such test of the 'Bravo' vehicle over a flame trench is depicted in Figure 6.

\section{B. Tether Testing}

For tether tests the vehicle is suspended from a crane as shown in Figure 4 to enable testing of the propulsion and integrated GN\&C without the risk of a vehicle departure or crash. The goal of these tests is typically to ascend 5 to 15 feet vertically and up to 10 feet laterally and hover in place for a preprogrammed duration. Upon successful completion of the hover, the vehicle descends and "lands" at the end of the tether.

Due to the potential dynamic loads during tethered flight, a substantially

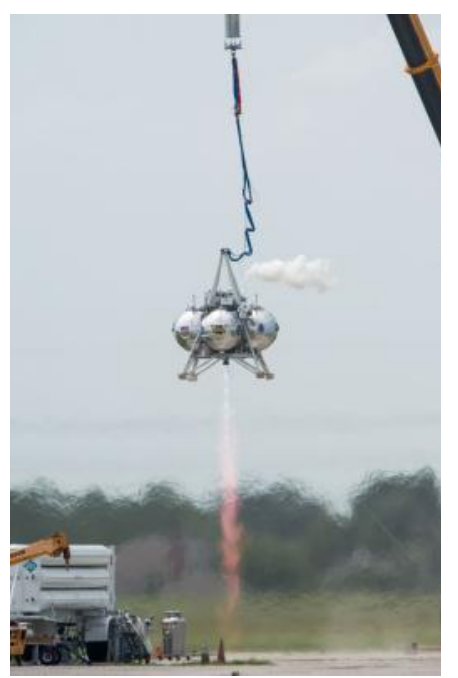

Figure 7 - Morpheus 1.5

'Bravo' executing a Tether Test in July 2013 
larger 120-ton crane is used for this testing. An energy absorber in line with the tether reduces the loads on both the crane and Morpheus vehicle and helps prevent damage to either asset.

Tether testing provides the first opportunity to perform integrated testing of the Morpheus vehicle with closedloop GN\&C. The primary objective of tether testing is to demonstrate 6 degree-of-freedom (DOF) GN\&C for vertical translation, hover and simulated landing operations. An additional objective is to understand and rapidly refine the integrated performance of avionics, propulsion, and GN\&C without risk of a vehicle crash.

\section{Free-Flight Testing}

Morpheus "free-flights" demonstrate the fully integrated flight capability of the vehicle with no restraints. Freeflight safeguards are automatic on-board aborts, remotely commanded aborts, as well as the redundant and independent TTS that can be activated by spotters who visually determine trajectory deviations. A variety of freeflight trajectories can be flown to incrementally build up to a fully functional Morpheus lander capable of flying planetary landing trajectories.

\section{MoRPheus 1.0 Test CAMPAigN}

During the Morpheus 1.0 test campaign, a series of three hot-fire tests was conducted to refine propulsion system performance. This was also the first opportunity to test vehicle hardware and software together. Due to the fast pace of development, these tests were used as verification tests for numerous software routines.

The Morpheus team completed these three hot-fire tests in 8 days and successfully demonstrated all test objectives except for handover from propulsion to GN\&C. The team quickly resolved all issues and confirmed solutions in subsequent tests, gaining valuable vehicle operations experience and confidence to proceed with tether testing.

Immediately following the hot-fire tests, five tether tests were conducted between April 25th and June 1st, 2011, with the primary objective to demonstrate stable 6-DOF GN\&C. The rapid schedule of the first four tests was driven by a demonstration flight planned for the JSC Innovation Day event on May 4th.

The most dramatic tether test in this test campaign was TT2. Immediately upon engine ignition, an H-bridge circuit controlling the throttle valve failed fully open $(+100 \%$ throttle). The vehicle rapidly ascended and an asymmetric bungee arrangement caused a pitching moment. When the ignition sequence was complete and control was handed
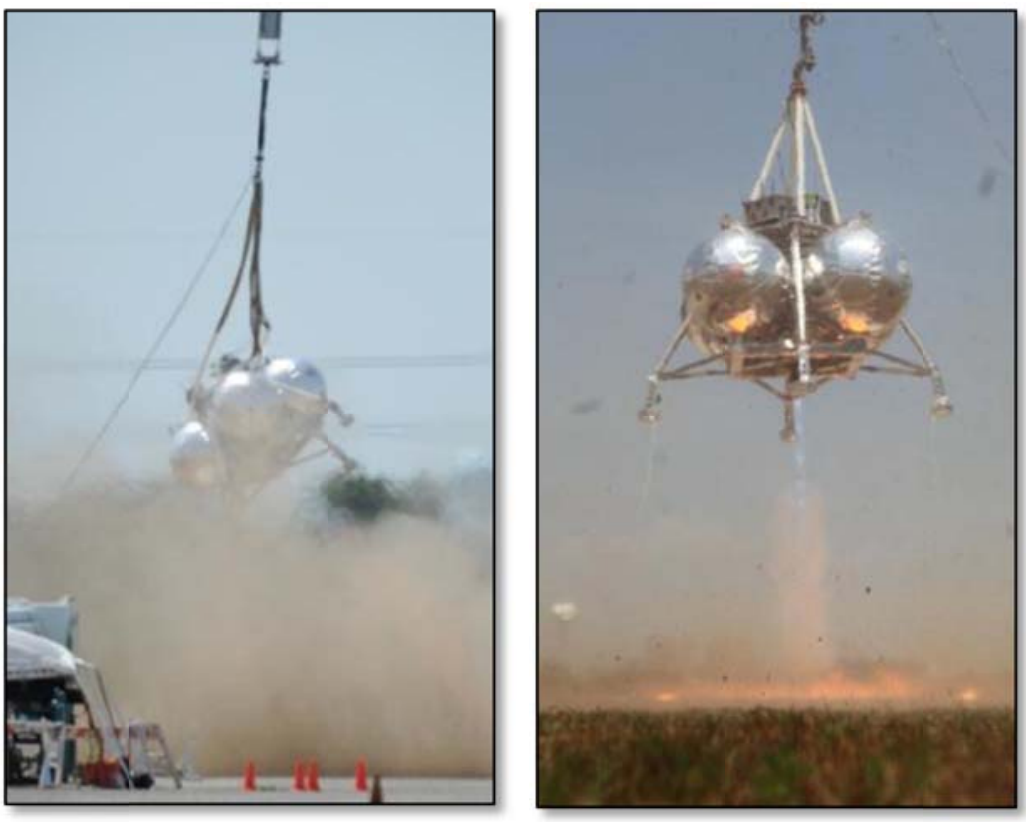

Figure 8 - Morpheus Tether Test 2 (TT2); and Tether Test 5 (TT5) over to GN\&C, the vehicle was already in an unrecoverable trajectory. To make matters worse, the GN\&C system contained a 90-degree clocking error in an IMU coordinate frame, preventing it from stabilizing the vehicle motion.

This uncontrolled motion continued despite on-board software and ground commands for soft and hard abort and engine shutdown. These primary abort methods rely upon shutting the throttle valve, which was stuck open. After 13 seconds of erratic "tetherball" flight, engine thrust was terminated by manual activation of the wired TTS.

The team would not have chosen such dynamic test conditions. Yet this "test failure" provided a training opportunity for the team to execute a safe abort, and identified key systems issues, enabling the team to improve the engine throttle valve design and correct the navigation frame transformation error. No vehicle or property damage resulted from this test, and the team turned around the VTB for another test in less than a week.

The vehicle was better behaved during TT5, successfully completing a full duration run with nominal engine shutdown after 42 seconds. Hover performance was improved, producing only a minor wobble with a period of 
approximately 3.2 seconds. The engine performed nominally and reached a steady-state temperature for the first time during VTB 1.0 testing. Testing of the 1.0 configuration came to an end when the HD3 engine suffered a burn-through event during throttle-up for tether test 6. A new engine design iteration, new avionics, GNC, software, and other upgrades were incorporated onto the vehicle to form the $1.5 \mathrm{~A}$ vehicle assembly.

\section{MORPHEUS 1.5 'ALPHA' TEST CAMPAIGN}

The Morpheus 1.5A test campaign began in February 2012. Three hot fire tests, one ground hot fire and fourteen tether tests were performed, accumulating over 870 seconds of runtime on the HD4 engine. The tether tests were opportunities for the design team to continue to characterize and improve the interaction between the GN\&C and

Table 2. Morpheus 1.5 ‘Alpha’ Test Summary

\begin{tabular}{|c|c|c|}
\hline Test \& Date & Objectives & Notes \\
\hline $\begin{array}{c}\text { HF5 } \\
2 / 27 / 12 \\
\end{array}$ & $\begin{array}{l}\text { Engine firing } \\
\text { test }\end{array}$ & $\begin{array}{l}40 \text { sec burn time } \\
1^{\text {st }} \text { test of HD4 on VTB } 1.5\end{array}$ \\
\hline $\begin{array}{c}\text { TT7 } \\
3 / 5 / 2012\end{array}$ & Hover test & $\begin{array}{l}30 \text { sec burn time } \\
\text { Low pressure at liftoff; Burn-through false alarm }\end{array}$ \\
\hline $\begin{array}{c}\text { TT8 } \\
3 / 13 / 2012 \\
\end{array}$ & Hover test & $\begin{array}{l}55 \text { sec burn time } \\
\text { Good } 40 \text { sec hover with GN\&C oscillations }\end{array}$ \\
\hline $\begin{array}{c}\text { TT9 } \\
3 / 16 / 2012 \\
\end{array}$ & Hover test & $\begin{array}{l}47 \mathrm{sec} \text { burn time } \\
\text { GN\&C algorithm issue led to TTS activation }\end{array}$ \\
\hline $\begin{array}{c}\text { HF6 } \\
4 / 2 / 2012 \\
\end{array}$ & $\begin{array}{l}\text { Short hold-down } \\
\text { test on pad }\end{array}$ & $\begin{array}{l}5 \text { sec burn time } \\
\text { Liftoff environment; Footpads overheated }\end{array}$ \\
\hline $\begin{array}{c}\text { TT10 } \\
4 / 4 / 2012\end{array}$ & Hover test & $\begin{array}{l}62 \text { sec burn time } \\
\text { GN\&C altitude issue }\end{array}$ \\
\hline $\begin{array}{c}\text { TT11 } \\
4 / 11 / 2012 \\
\end{array}$ & Hover test & $\begin{array}{l}56 \text { sec burn time } \\
\text { Stable altitude control; Lateral oscillations }\end{array}$ \\
\hline $\begin{array}{c}\text { TT12 } \\
4 / 18 / 2012 \\
\end{array}$ & Hover test & \begin{tabular}{|l}
69 sec burn time \\
45 sec hover (longest yet); Lateral oscillations \\
\end{tabular} \\
\hline $\begin{array}{c}\text { TT13 } \\
5 / 2 / 2012 \\
\end{array}$ & Hover test & $\begin{array}{l}62 \mathrm{sec} \\
\text { Stable } 45 \text {-sec hover with improved lateral stability } \\
\end{array}$ \\
\hline $\begin{array}{c}\text { TT14 } \\
5 / 8 / 2012 \\
\end{array}$ & Hover test & $\begin{array}{l}66 \mathrm{sec} \\
\text { Stable 45-sec hover with improved lateral stability }\end{array}$ \\
\hline $\begin{array}{c}\text { TT15 } \\
5 / 10 / 2012 \\
\end{array}$ & Hover test & $\begin{array}{l}60 \mathrm{sec} \\
\text { Stable hover at } 8 \text { ' with a planned soft abort }\end{array}$ \\
\hline $\begin{array}{c}\text { TT16 } \\
6 / 11 / 2012\end{array}$ & $\begin{array}{l}\text { Hover test with } \\
\text { ALHAT }\end{array}$ & $\begin{array}{l}41 \mathrm{sec} \\
\text { Stable two-level hover at } 5 \text { feet and } 8 \text { feet, with ALHAT } \\
\text { targeting and HDS tests }\end{array}$ \\
\hline $\begin{array}{c}\text { TT17 } \\
6 / 18 / 2012 \\
\end{array}$ & $\begin{array}{l}\text { Hover test with } \\
\text { ALHAT }\end{array}$ & $\begin{array}{l}64 \mathrm{sec} \\
\text { Stable two-level hover with ALHAT targeting and HDS tests }\end{array}$ \\
\hline $\begin{array}{l}\text { RCS HF1 } \\
7 / 3 / 2012\end{array}$ & $\begin{array}{l}\text { RCS hot fire } \\
\text { testing (no main } \\
\text { engine) }\end{array}$ & $\begin{array}{l}31 \text { tests of LOX/methane RCS engines } \\
\text { Range of ignition conditions (temperature, spark duration) }\end{array}$ \\
\hline $\begin{array}{c}\text { TT18 } \\
7 / 6 / 2012 \\
\end{array}$ & Hover test & $\begin{array}{l}49 \mathrm{sec} \\
\text { Stable two-level hover; Post-flight active methane RCS test }\end{array}$ \\
\hline $\begin{array}{c}\text { TT19 } \\
7 / 19 / 2012 \\
\end{array}$ & Hover test & $\begin{array}{l}72 \mathrm{sec} \\
\text { Nominal 60-second hover; Post-flight methane RCS test }\end{array}$ \\
\hline $\begin{array}{c}\text { TT20 } \\
8 / 3 / 2012 \\
\end{array}$ & Hover test & $\begin{array}{l}50 \text { sec hover } \\
\text { First tether test at KSC; Post-flight methane RCS test }\end{array}$ \\
\hline $\begin{array}{c}\text { FF1 } \\
8 / 7 / 2012\end{array}$ & Free flight & $\begin{array}{l}<5 \mathrm{sec} \\
\text { First attempt at free flight had automatic soft abort due to } \\
\text { false engine burn-through indication }\end{array}$ \\
\hline $\begin{array}{c}\text { FF2 } \\
8 / 9 / 2012\end{array}$ & Free flight & Loss of vehicle shortly after liftoff due to stale IMU data \\
\hline
\end{tabular}
propulsion systems. Table 2 lists the test summary for Morpheus 1.5 'Alpha'.

After HF5 confirmed the performance of the new HD4 engine, the team began the assessment of the integrated VTB 1.5 performance in tethered hover tests. Notable tests include TT9, which revealed a GN\&C algorithm issue that caused the vehicle to exceed the altitude constraint, leading to activation of the TTS to abort the test. TT9 proved the value of the in-line energy absorber and the very robust vehicle construction in preventing damage to VTB 1.5 as it dropped to the end of the tether.

As the first test of Morpheus sitting on the launch pad in liftoff configuration, HF6 provided valuable ground effects and overpressure data, and revealed that the footpads were insufficiently insulated. This test served as a proto-qual test, intended to envelope the environments expected to be experienced during free flight launches. Tether tests 10 through 15 demonstrated increasing vehicle controllability and stability with nominal engine shutdowns as the team refined GN\&C and EMA parameters. With satisfactory vehicle 
performance, the ALHAT suite of sensors was integrated with the vehicle for two tether tests. This initial integration did identify some hardware and software timing discrepancies that required continued maturation once the sensors were removed from the vehicle.

With ALHAT integration testing complete, the team prepared for free flight testing by conducting one final tether test at JSC, shipping the vehicle to KSC, and then conducting a tether test at KSC's Shuttle Landing Facility (SLF) to verify transportation did not impact vehicle readiness.

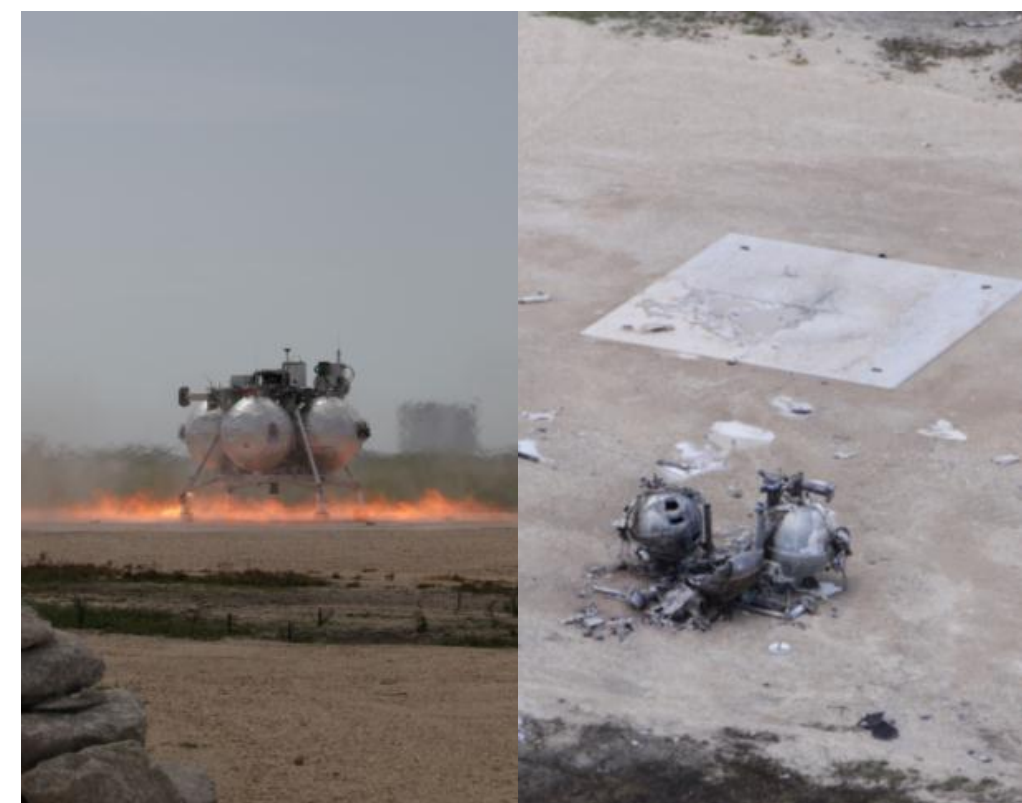

Figure 9 - Shuttle Landing Facility at KSC: Morpheus Free Flight 1at ignition; and Free Flight 2 after it crash landed.

A hazard field - replicate of an area of the lunar surface - was constructed off the end of the SLF runway as the approach field for the Morpheus free flight testing. The initial test campaign at KSC, though, was intended to incrementally expand the flight envelope to demonstrate adequate vehicle performance before reintegrating the expensive ALHAT sensors. On August 7, 2012, Free Flight 1 was aborted just after liftoff due to a faulty transient engine burn-through indication. The vehicle detected the indication and softaborted as designed - after rising less than a foot off of the pad. Free Flight 2 was attempted two days later. In this test, the data from the only active IMU was lost 0.6 seconds into flight, causing the vehicle to lose control and crash. The entire vehicle was lost, with the exception of a handful of parts that were recovered. Most notably, the HD4 engine injector was recovered and reusable, and has been incorporated into the rebuilt engine currently powering the 'Bravo' vehicle. A separate paper is being produced to discuss the findings of the crash investigation and corrective actions applied to the build and operation of the ‘Bravo’ vehicle.

Table 3. Morpheus 1.5 ‘Bravo’ Test Summary

\section{MoRpheus 1.5 \\ 'BRAVO' TEST CAMPAIGN}

The loss of Morpheus 1.5 'Alpha' resulted in a rebuild effort to return to testing. 70 upgrades were approved for incorporation into the 'Bravo' vehicle, as well as GSE, operations and test facilities. Rebuild efforts began in earnest in October 2012 with the first integrated hot fire test completed six months later. To date, two hot fire tests, a ground hot fire over a newly installed flame trench, and 8 tether tests

\begin{tabular}{|c|c|c|}
\hline Test \& Date & Objectives & Notes \\
\hline $\begin{array}{c}\text { HF7 } \\
4 / 23 / 2013 \\
\end{array}$ & $\begin{array}{l}\text { Ignition testing } \\
\text { Methane RCS testing }\end{array}$ & Tests of engine start box and combustion stability \\
\hline $\begin{array}{c}\text { HF8 } \\
5 / 1 / 2013\end{array}$ & Hot fire test & $50 \mathrm{sec}$ \\
\hline $\begin{array}{c}\text { HF9 } \\
5 / 16 / 2013\end{array}$ & $\begin{array}{l}\text { Ground hot fire, low } \\
\text { altitude ( } 3 \mathrm{ft} \text { ) hot fire }\end{array}$ & $\begin{array}{l}6 \text { sec } \\
\text { Two } 3 \text { sec tests in hold-down configuration over flame trench }\end{array}$ \\
\hline $\begin{array}{c}\text { TT21 } \\
5 / 24 / 2013\end{array}$ & Hover test & $\begin{array}{l}11 \mathrm{sec} \\
\text { Automatic soft abort due to lateral range violation }(>4 \mathrm{~m})\end{array}$ \\
\hline $\begin{array}{c}\text { TT22 } \\
6 / 6 / 2013\end{array}$ & Hover test & $\begin{array}{l}60 \text { sec } \\
\text { Stable hover }\end{array}$ \\
\hline $\begin{array}{c}\text { TT23 } \\
6 / 11 / 2013 \\
\end{array}$ & Hover test & $\begin{array}{l}25 \text { sec; Soft abort commanded due to loss of telemetry } \\
\text { Flight test using backup IMU }\end{array}$ \\
\hline $\begin{array}{c}\text { TT24A } \\
6 / 14 / 2013 \\
\end{array}$ & Hover test & $\begin{array}{l}12 \mathrm{sec} \\
\text { Automatic soft abort due to lateral range violation }(>4 \mathrm{~m})\end{array}$ \\
\hline $\begin{array}{l}\text { TT24B } \\
6 / 14 / 2013\end{array}$ & Hover test & $\begin{array}{l}30 \text { sec Stable hover } \\
\text { Test of manual downmode to backup IMU }\end{array}$ \\
\hline $\begin{array}{c}\text { TT25 } \\
7 / 11 / 2013 \\
\end{array}$ & $\begin{array}{l}\text { Hover test with } \\
\text { ALHAT }\end{array}$ & $\begin{array}{l}11 \mathrm{sec} \\
\text { Automatic soft abort due to lateral range violation }(>4 \mathrm{~m})\end{array}$ \\
\hline $\begin{array}{c}\text { TT26 } \\
7 / 23 / 2013\end{array}$ & $\begin{array}{l}\text { Hover test with } \\
\text { ALHAT }\end{array}$ & $\begin{array}{l}55 \text { sec Stable hover } \\
\text { ALHAT automatic moding and performance } \\
\text { Test of manual downmode to backup RCS (helium) }\end{array}$ \\
\hline $\begin{array}{c}\text { TT27 } \\
7 / 26 / 2013\end{array}$ & $\begin{array}{l}\text { Hover test with } \\
\text { ALHAT }\end{array}$ & $\begin{array}{l}81 \mathrm{sec} \\
\text { ALHAT automatic moding and performance } \\
\text { High thrust, long duration; Planned lateral motion }(1 \mathrm{~m})\end{array}$ \\
\hline $\begin{array}{l}\text { TT28 } \\
8 / 7 / 11\end{array}$ & Hover test & $\begin{array}{l}77 \mathrm{sec} \\
\text { Quad ascent/descent guidance test; Planned lateral motion (3 m) } \\
\text { Mars soil plume impingement test (by JPL) }\end{array}$ \\
\hline
\end{tabular}

American Institute of Aeronautics and Astronautics: SPACE 2013 
have been conducted. Table 3 lists the test summary for Morpheus 1.5 'Bravo'.

The knowledge gained in testing the 'Alpha' vehicle significantly improved the performance characterization of the 'Bravo' vehicle once its testing began. However, there were a number of sticking points that needed attention. For one, 'Bravo' is a 200lb heavier vehicle and its engine produces 800lb more thrust than its predecessor. The change in mass properties, combined with some plumbing changes, led to an unacceptable susceptibility to propellant imbalances that caused a number of soft aborts during early tether testing. The abort box is a very stringent $4 \mathrm{~m}$ for tether testing, to prevent tether interaction and ensure crane protection. Tuning of guidance and

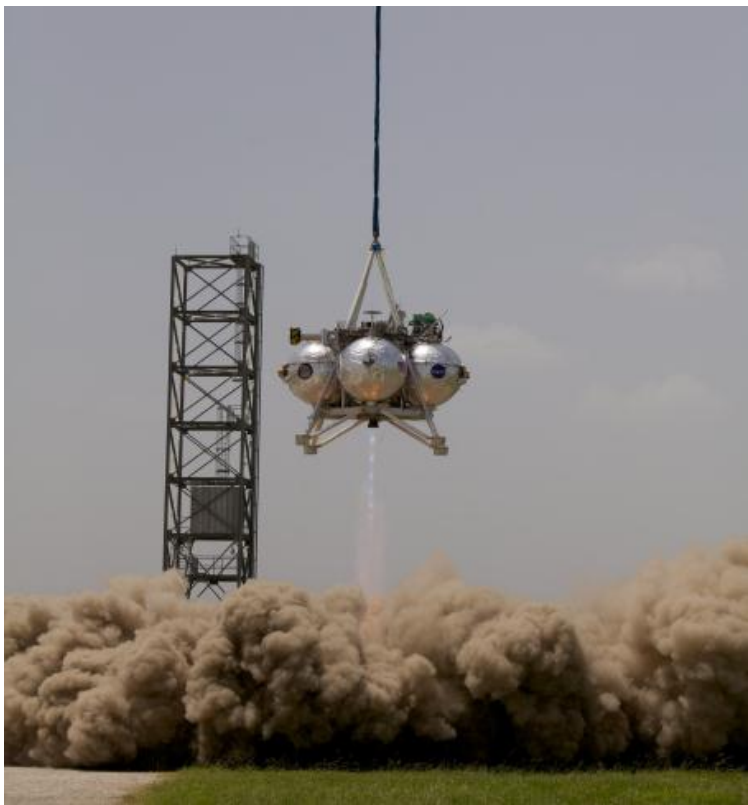

Figure 10 - Morpheus 1.5 'Bravo' executing a translational Tether Test in August 2013. Mars soil simulant was deployed on the launch pad to study plume impingement for the Mars 2020 program. control parameters eventually overcame the problem, allowing tether testing to proceed unhindered.

Improvements for 'Bravo' vehicle operations also included significantly enhanced flight simulation capabilities. Reliable simulation tools afforded the project the opportunity to predict vehicle performance under more risky tether flight profiles. Planned testing progressed from simple vertical hovers (all that was accomplished with $1.5 \mathrm{~A}$ in 2012) to multi-level vertical motion with lateral translations of up to $3 \mathrm{~m}$. This expanded capability enabled the testing of all different versions of gain scheduling through all phases of flight, which allowed the project to 'test like you fly' in preparation for future free flights at KSC.

Integration with the ALHAT instruments was repeated with the 'Bravo' vehicle during tether testing. Integrated performance was significantly improved from 2012, with nearly all discrepancies resolved and demonstrated HDS pointing accuracy within 0.15 degrees. Additionally, the project collaborated with the Mars 2020 Program from the Jet Propulsion Laboratory by incorporating a plume impingement study using Mars soil simulant during a tethered test. A photo taken shortly after ignition is included as Figure 9.

One final new test is planned before the team moves to KSC to begin free flight campaigns. A Ground Takeoff and Landing (GTAL) test, while still constrained via tether, will be conducted at JSC in September 2013. The concept is to buy down risk by demonstrating liftoff over a flame trench followed by a nominal translation, descent and landing back on the ground. The tether only provides range safety and will minimize any damage if there is a problem during the test. This will be the last test planned at JSC before the vehicle is moved to KSC for testing at the SLF.

\section{LESSONS LEARNED AND LEAN DEVELOPMENT TENETS}

In addition to the technological advancements, another objective of the Morpheus Project is to change perceptions and attitudes about what can be done, what should be done, and what is possible. It is about a return to the fundamental engineering design practices. It is about developing a workforce that will have the skills and capabilities to build the next generation of spacecraft and space systems to enable human exploration beyond low earth orbit. As a result, Morpheus strives to:

- Provide hands on work to civil servants and some key contractor partners

- $\quad$ Understand the underlying engineering trades and drivers through and testing simple analysis

- Build prototypes early and often to drive out design issues, operational concepts, and flight requirements

- $\quad$ Test relentlessly

- $\quad$ Take smart risks

- Strive toward simple designs

- $\quad$ Accept the risk of test failures in order to learn, iterate, and advance more quickly

- Encourage openness and curiosity regarding new design and analysis techniques 
- Leverage off existing facility and institutional capacity

- Leverage and coalesce existing efforts and technology

- $\quad$ Build and manage a coalition of innovative and traditional partnerships

The design, development, testing, and operations of this project leverage technology work in the Agency that has been ongoing, partnerships that have been in place for many years, and facilities and resources that already exist. Integrating into a flying demonstration platform provides a means to mature those leveraged technologies and thereby enable more cost effective human space flight.

\section{A. Project Rigor}

The real trick to sustainable lean development is finding the right level of rigor and discipline appropriate for the particular project under consideration. The following graphic illustrates the concept as applied to the prototype Morpheus lander.

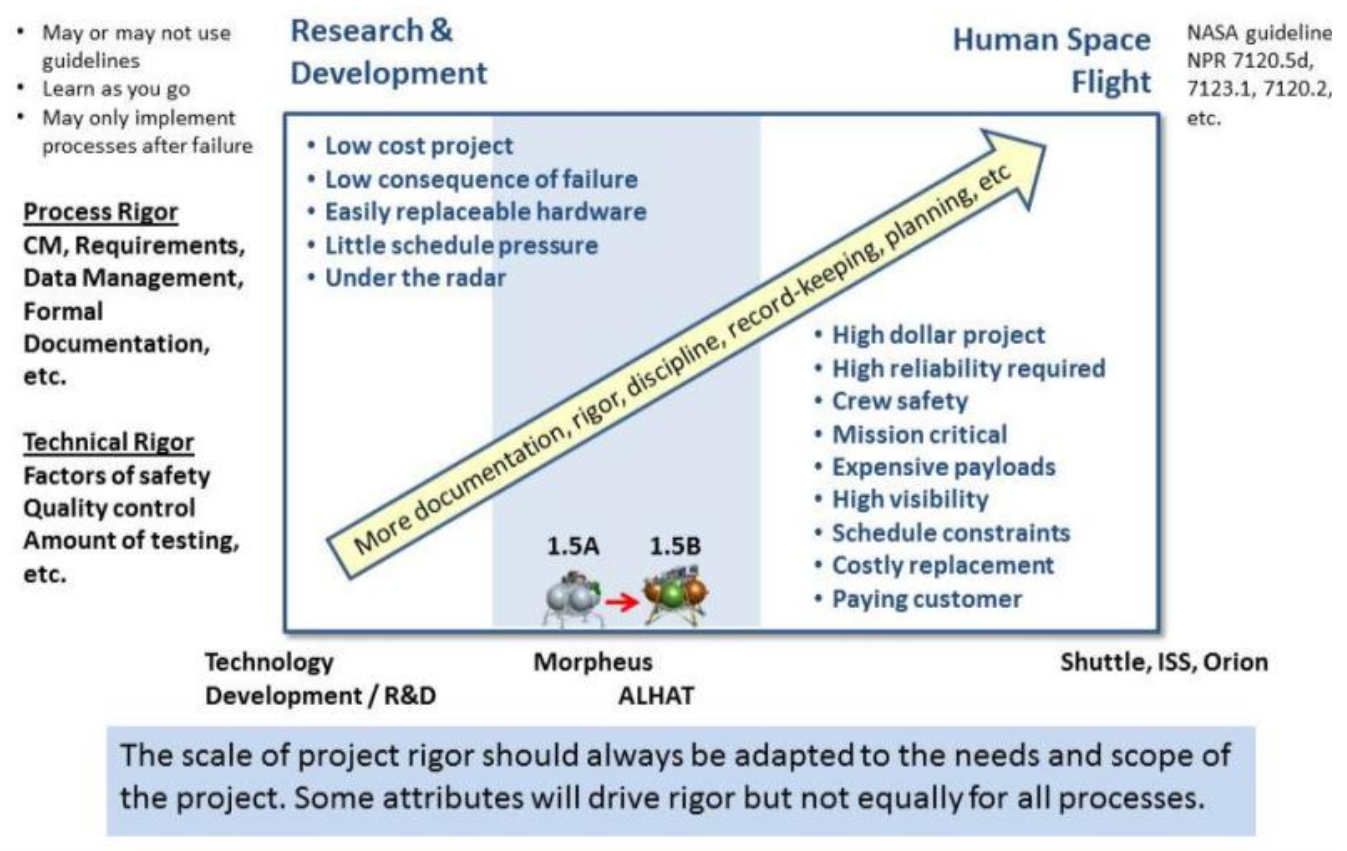

Figure 11 - Morpheus Scale of Rigor.
The $\mathrm{X}$-axis of the graph shows some

representative programs, projects, or organizations, while the $\mathrm{Y}$-axis represents rigor in the form of configuration management, requirements development and flow down, safety reviews, decision board hierarchy, or any other number of mechanisms and processes used to add rigor, repeatability, redundancy or discipline into

the execution of a spaceflight mission.

There was little opportunity in recent decades to develop completely new human spaceflight systems until the Constellation Program was formulated. NASA has gone a generation since building a piloted spacecraft. Many of the best talent in the Agency have spent their entire careers in the sustaining or operational phase of the Shuttle and ISS Programs. Because of these factors it is difficult for our workforce to move toward the left of Figure 1. It actually helps to work with some of the aerospace startups in order to see the other extreme and enable intelligent choices as to the "right" rigor for a development or prototype system. Ultimately however there is no formula for determining the "right" level of any of these attributes; it must be agreed on by the project leadership. "It is not about having process or not having process, it is about the right level of process at the right time”.

\section{B. Risk Culture}

Also key to lean development is accepting appropriate risk. The project must be very clear about what risk is acceptable. For early development and testing of engineering prototypes, accepting the complete loss of the prototype or engineering unit may be appropriate. This doesn't mean the project behaves irresponsibly or unprofessionally. Rather, it is simply a realization that you build prototypes because you don't have all the answers, and testing and trying different designs leads to answers. Sometimes those tests will fail, sometimes spectacularly. The project must manage appropriate and acceptable risk, acceptance of "failure", and expectations of "success" in technology development. 
To be clear, this risk acceptance applies only to technical performance of the vehicle system. Hazards to personnel safety or infrastructure are managed at a much higher level of rigor, commensurate with all other activities done within the Agency.

\section{Team Depth}

By their very nature, lean teams with low budgets and fast-paced schedules will not be deep in all areas. Nor will they be able to root out all potential design or operational inadequacies. This is a form of risk that needs to be accepted in order to pursue the aforementioned philosophy. Decisions need to be made routinely to minimize the amount of risk to the project's success while still maintaining budget and schedule. Proto-qual approaches generally can be sufficient, but there are times when they won't sufficiently identify technical risks, and the project needs to be positioned to accept the consequences.

Build Engineering Prototypes

- If you wait to build the perfect thing, you won't get to, and it won't be perfect anyway

- Engineering prototypes are for learning and failing quickly

- Build, fail, improve, repeat

\section{Communication}

Commensurate with the delineated approach to risk acceptance is the imperative to ensure that all potentially affected parties have a sufficient understanding of the risk posture and the responses necessary for any risk that comes to fruition. Significant effort went into discussing the potential consequences of flying a single-string VTB built quickly with a low budget and borrowed parts. It was understood and accepted across the Agency that the knowledge gained and advances made using the Morpheus vehicle configuration were worth the risk of losing the vehicle during a flight test. This pre-test declaration of vehicle loss as strictly a test failure was critical in enabling the team to quickly recover and rebuild while pursuing an appropriate engineering investigation into the test failure.

\section{E. Partnering}

Specifically partnering with external non-traditional partners can be beneficial. Those partners bring innovation and new methods. Non-traditional partners validate your own good processes and shine a light on your inefficiencies. It is often difficult to see how to improve your own processes when that is all you know. Even when improvements can be identified they are often incremental and seldom revolutionary, because all the data is grounded in familiar processes. Partners often can help show other ways and other possibilities.

The Morpheus project teams with key partners in industry (including emerging aerospace companies), academia, centers within NASA, other government agencies, and international partners. All teaming arrangements are based upon the technology, hardware, or expertise that partners brings to bear. The project also continuously seeks innovative and unconventional non-aerospace partnerships.

\section{F. Create a Sense of Urgency}

Every day matters. Every meeting is important or don't have it. Products are good, but products delivered quickly make all the difference. A sense of urgency makes the team intolerant of inefficiency. It drives innovation and spurs other ways of doing business. It excites and motivates. The milestone needs to be barely achievable. If it is too far away we tend to think too much. We take time to plan and analyze and re-analyze. We debate and consider. We work on things in Stephen Covey's quadrant of important-but-not-urgent and when you have a lot of time the list of "important” becomes long. We develop elaborate organizational constructs.

Given too little time we don't commit. We don't believe, we know the schedule will slip and we try only to not be the system that publicly causes the slip. We don't try to be the fastest camper running from the bear; we only try to be a bit faster than the slowest.

The key is a believable but challenging and audacious time constraint. Then we innovate and maximally leverage our capabilities. It is then when we break down barriers, work our best as a team, and truly do great things.

\section{G. “Home Depot” Engineering}

NASA often forgets our roots in building prototypes and performing relentless testing. For lean development it is imperative to foster and encourage "Home Depot" engineering - the act of building prototypes and engineering tests with simple hardware at hand. This allows quick and cheap understanding of the physics, how things go together, and cheaply evaluates competing concepts. 
Morpheus slosh testing provides a good example. Two thirds of the mass of a lunar lander is propellant, so propellant slosh is important to understand and manage. The first prototype the project built used existing propellant tanks that did not have slosh baffles. For the current VTB, however, the team wanted to include baffles for a flight vehicle configuration. Team engineers needed to understand and simulate slosh for a four tank configuration, and validate simulations with a
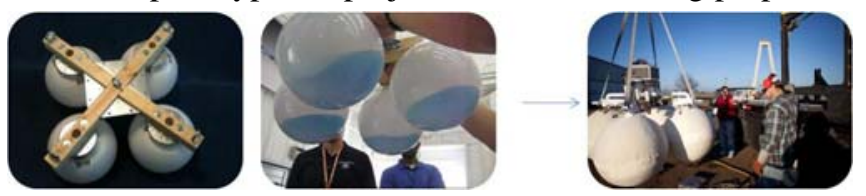
full scale slosh characterization test on the vehicle. The team quickly built the small prototype shown below with $\$ 60$ worth of Home Depot hardware. Tests with this model provided data to anchor the computer simulation, evaluate competing techniques for performing the full scale test, and more importantly gave the engineers an intuitive feel for the slosh dynamics which led to an elegant design for Morpheus propellant tank baffles.

\section{CONCLUSIONS}

The Morpheus Project has provided an opportunity for a mostly civil servant team to conduct end-to-end vehicle flight operations with a terrestrial vertical test bed, and to advance integrated technologies that will benefit human spaceflight. Each flight test opportunity provided valuable insights, even when test objectives were not fully met. The team thrives on a project culture that recognizes the value of testing, failing, and recovering quickly to move forward and test again.

The appropriate level of rigor in team processes and methodologies enabled the Morpheus Project to progress rapidly and successfully along the path to flight testing. The fast pace and small size of the Morpheus team necessitated innovative solutions for team collaboration and communication, as well as a project management culture that expected any process or "overhead" to buy its way into the project based upon merit.

Commercial partners such as Armadillo Aerospace, a very small and relatively new company on the space scene, provided the NASA team with visibility into commercial project execution and systems engineering, and these partners in turn gained more insight into the NASA safety and project management cultures. Commercial space companies use a wide range of approaches for their projects, as do various NASA organizations and programs. Considering a full range of commercial and NASA options, Morpheus tailored an approach that has more rigor than typically employed for "technology development" but less than that used for "human space flight."

\section{SUMMARY}

NASA's Morpheus Project has developed and tested a prototype planetary lander capable of vertical takeoff and landing, designed to serve as a testbed for advanced spacecraft technologies. The Morpheus vehicle has performed successfully a set of integrated vehicle test flights including hot-fire and tether tests, which will ultimately culminate in a $1 \mathrm{~km}$ slant range surface approach trajectory with autonomous hazard avoidance and precision landing. This development and testing campaign has been conducted on-site at JSC, with initial tests occurring less than one year after project start. Designed, developed, manufactured and operated in-house by engineers at JSC, with a number of partners, the Morpheus Project represents an unprecedented departure from recent NASA programs and projects that traditionally require costlier and longer development lifecycles and testing at remote, dedicated testing facilities.

In early FY13, Morpheus rebuilt a 'Bravo' vehicle after loss of the 'Alpha' vehicle, and made a number of upgrades and improvements to the vehicle and ground subsystems, including integration of the Autonomous Landing and Hazard Avoidance Technology (ALHAT) Project's hardware and software components. These upgrades will provide improved performance, expanded capabilities, and better robustness for an extended test campaign that will culminate in high energy trajectories that simulate a landing approach on a lunar, asteroid or planetary surface. The initial test campaign at JSC will be followed by free flights and high energy trajectories at KSC.

As mentioned previously, a project goal is demonstration of a few key technologies. These technologies have been maturing separately on their own schedules. The Morpheus Project provides a focus and an opportunity to demonstrate these technologies in a relevant flight environment. Too often, technologies are not developed to a level at which a program or project can utilize them. Because of that, such technologies often are deemed too risky for adoption by large scale development programs. Thus, large scale development programs are inherently incremental, failing to fully drive the state of the art in space systems, unable to realize cost savings through innovative approaches. By focusing key technologies on a flight demonstration, these technologies will become capabilities available for a multitude of other applications. 
While lunar landers were used successfully during the Apollo era, there were certain risks taken with Apollo that NASA intends to reduce or eliminate in future such vehicles, both manned and unmanned. ALHAT technology will also allow us to safely land on various planets, moons, and asteroids at essentially any desired surface location under any lighting conditions. ALHAT sensors and software package have to be tested and demonstrated to achieve the necessary technology readiness level, TRL 6. Following the terrestrial flight tests with a successful space demonstration (e.g., safe landing on the Moon), the targeted technologies of LOX/methane propulsion and the ALHAT system can be elevated to TRL 9, and can be used safely for future robotic or manned vehicles at any destination in the solar system.

\section{BIOGRAPHIES}

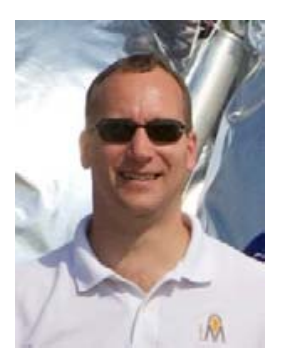

Jon B. Olansen, PhD - Dr. Olansen serves as the Project Manager for the Morpheus Project. He began his career as a Space Shuttle flight controller, supporting 32 missions and logging $>4200$ hours in Mission Control. Jon earned his B.S. in Aerospace Engineering and M.S. in Mechanical Engineering from the University of Notre Dame. He obtained his Ph.D. in Mechanical Engineering (Biomedical Focus) as a National Instruments Fellow at Rice University, where he specialized in biomedical experimentation in electrophysiology and cardiopulmonary hemodynamics. He has published several journal articles related to his research and authored a reference book on biomedical instrumentation. He returned to NASA to represent the Astronaut Office in the design, development, and operation of human life sciences experiments destined for the International Space Station. Dr. Olansen has since held a number of positions of increasing responsibility including tours in Safety \& Mission Assurance, the Shuttle Program Office and the Exploration Systems Mission Directorate at NASA Headquarters, before undertaking his current role.

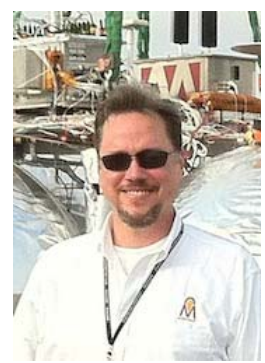

Stephen R. Munday - Mr. Munday serves as the Deputy Project Manager for the Morpheus Project. His NASA career spans 26 years as a lead engineer, technical board chairman, system manager, and international technical liaison for various NASA programs including the X-38 Crew Return Vehicle, Space Shuttle, Orion Crew Exploration Vehicle, and International Space Station (ISS). His engineering expertise is primarily in the fields of aerodynamics and GN\&C. Prior to joining the Morpheus team, he spent 4 years helping to manage NASA's Moscow Technical Liaison Office in Russia's Mission Control Center and in the Baikonur Cosmodrome in Kazakhstan on behalf of the ISS Program. Mr. Munday holds an M.S. degree in Aerospace Engineering (G\&C focus) from the University of Texas in Austin, an M.S. in Computer Engineering from the University of Houston at Clear Lake, and a B.S. in Aerospace Engineering (aerodynamics focus) from the University of Missouri - Rolla (now the Missouri Univ of Science \& Technology).

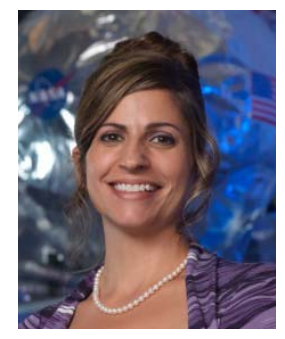

Jennifer L. Devolites - Ms. Devolites graduated from Texas A\&M University with a Bachelors Degree in Aerospace Engineering. She has worked at NASA JSC for 21 years in a number of technical and management roles on projects including Simplified Aid for Extravehicular Activity Rescue (SAFER), Autonomous Miniature Robotic Camera (AERCam), Internatlonal Space Station Guidance, Navigation and Control (ISS GN\&C), X38, Exploration Technology Development Program Automated Rendezvous and Docking Sensor Technology Project (ETDP AR\&DSTP), and Orion GN\&C. She has served as the systems engineering and integration lead for Project Morpheus since 2009. 